\title{
O ABORTO NA MÍDIA: MULTIPLICIDADE DE PRÁTICAS DISCURSIVAS SOBREDIREITO E CRIME
}

\author{
Cristianne Maria Famer Rocha ${ }^{1}$ \\ Rosana Maffacciolli ${ }^{2}$ \\ Marisangela Spolaôr Lena ${ }^{3}$ \\ Mateus Aparecido de Faria ${ }^{4}$ \\ Rosane Machado Rollo 5 \\ Nathalia Zorzo Costa ${ }^{6}$
}

Resumo: No Brasil, em agosto de 2018,

o Superior Tribunal Federal convocou audiência pública para debater a descriminalização do aborto até a décima segunda semana de gestação. No mesmo período, na Argentina, mobilização política semelhante ocorreu com a votação no Senado de uma lei que descriminalizaria a prática do aborto no país. Diante das inúmeras manifestações que tais eventos suscitaram, com diferentes repercussões midiáticas, objetivamos identificar e analisar as reportagens sobre o aborto veiculadas em dois jornais de ampla circulação nacional, em suas versões online. Entre 12 de julho e 13 de agosto de 2018, realizamos uma pesquisa documental, exploratória e descritiva, de abordagem mista, nos sites da Folha de São Paulo e do El País (versão Brasil). Foram selecionadas 79 reportagens. A maioria (29) se referia à legislação e regulamentação do aborto na Argentina e, na sequência, no Brasil (26). A análise dos resultados permitiu concluir que, a

\footnotetext{
${ }^{1}$ Doutora e Mestre em Educação pela Universidade Federal do Rio Grande do Sul (UFRGS), Professora Associada da Escola de Enfermagem/UFRGS. Email: cristianne.rocha@ufrgs.br

${ }^{2}$ Doutora e Mestre em Enfermagem pela Universidade Federal do Rio Grande do Sul (UFRGS). Email: rosanamaffac@yahoo.com.br

${ }^{3}$ Doutoranda em Saúde Coletiva junto à Universidade do Vale dos Sinos (UNISINOS), Mestre em Psicologia junto à Universidade Federal de Santa Maria (UFSM). Email: marisangelaslena@gmail.com

${ }^{4}$ Mestre em Saúde Coletiva pelo Instituto René Rachou - Fundação Oswaldo Cruz (Fiocruz). TécnicoAdministrativo em Educação na Universidade Federal de Minas Gerais (UFMG). Email: mateusfaria18@gmail.com

${ }^{5}$ Mestre em Saúde Coletiva pela Universidade Federal do Rio Grande do Sul (UFRGS), Bacharel em Saúde Coletiva (UFRGS). Email: rosanerollo@gmail.com

${ }^{6}$ Enfermeira e estudante do Curso de Bacharelado em Saúde Coletiva da Universidade Federal do Rio Grande do Sul (UFRGS). Email: nzorzo@gmail.com
} 
despeito da atenção que deveria receber, o tema ainda é pouco explorado pela mídia no Brasil, com a reprodução de argumentos de pouca profundidade crítica e técnica, geralmente desfavoráveis à realização do aborto.

Palavras-chave: Aborto. Aborto inseguro. Mídia. Comunicação em Saúde.

Abstract: In Brazil, in August 2018, the Federal Superior Court convened a public hearing to discuss the decriminalization of abortion until the twelfth week of gestation. In the same period, in Argentina, similar political mobilization occurred with the Senate voting on a law that would decriminalize the practice of abortion in the country. In view of the innumerable manifestations that these events aroused, with different media repercussions, we aimed to identify and analyze the reports about abortion published in two newspapers with wide national circulation, in their online versions. Between July 12 and August 13, 2018, we conducted a

${ }^{7}$ Embora reconheçamos que a expressão "Interrupção Voluntária da Gravidez" (IGV), ao invés de aborto - expresse de forma mais adequada a situação, decidimos usar a palavra documental, exploratory and descriptive research, with a mixed approach, on the sites of Folha de São Paulo and El País (Brazil version). 79 articles were selected. The majority (29) referred to the legislation and regulation of abortion in Argentina and, subsequently, in Brazil (26). The analysis of the results allowed to conclude that, despite the attention it should receive, the subject is still little explored by the media in Brazil, with the reproduction of arguments of little critical and technical depth, generally unfavorable to abortion.

Keywords: Abortion. Insecure abortion. Media. Health Communication.

\section{Panorama do Aborto no Brasil e no} Mundo

O aborto $^{7}$ é definido pela Organização Mundial de Saúde (OMS) como a expulsão do concepto com peso inferior a quinhentos gramas, até a vigésima segunda semana de gestação (DOMINGOS, 2010), podendo ser espontâneo ou provocado. Quando inserido na ilegalidade, acarreta em

aborto, em função de a mesma ser mais popularmente difundida no Brasil. 
graves consequências à saúde e pode ocasionar a morte da mulher, uma vez que nessa situação é realizado em condições precárias, com o uso de medicamentos abortivos, fora do sistema de saúde e na ausência de assistência clínica especializada.

Para essa problematização, cabe delimitar duas possibilidades de realização do aborto, cada qual com diferentes repercussões para a saúde das mulheres e para a sociedade como um todo. Uma delas é o aborto seguro o qual, respeitando as restrições legais de cada país, é realizado nos serviços de saúde e sob respaldo de protocolos clínicos e psicossociais que asseguram a integridade física e emocional das mulheres. $\mathrm{O}$ aborto inseguro, realizado sem amparo legal, não conta com o acesso a serviços de saúde formais e com a assistência necessária para evitar disfunções físicas e mentais nas mulheres, o que as expõem a elevado risco de morte e de seqüelas (WHO, 2013).

Recente estudo sobre a magnitude do problema revelou que, do ano de 2010 a 2014, foram realizados 55,7 milhões de abortos em todo o mundo. Pouco mais da metade, 54,9\%, ocorreu em condições
86 seguras. $\mathrm{O}$ restante, realizado em condições inseguras, ocorreu predominantemente $(97 \%$ dos abortos inseguros) em países em desenvolvimento, ou seja, em contextos políticos em que as leis são as mais restritivas e em que se verificam reações sociais mais coercitivas em relação ao aborto (GANATRA et al, 2018).

No Brasil, até o início do século XIX, o aborto não era configurado como crime. Com o Código Criminal de 1830, a prática passou a ser ilegal e passível de punição, quando realizado por terceiros. A partir do Código Penal de 1890, a prática, inclusive realizada pela própria mulher, também entrou para a ilegalidade, exceto nos casos de gravidez resultante de estupro ou que representasse risco à vida das mulheres (ANIS, 2012).

Segundo o Código Penal brasileiro vigente, $\mathrm{o}$ aborto é considerado um crime contra a vida, e a mulher que o realizar pode ser punida com a prisão. Sua prática é permitida nos casos em que a gestação ocorreu em virtude de violência sexual ou quando existe risco de morte para a gestante (BRASIL, 1940). Conforme a decisão do Supremo Tribunal Federal (STF) sobre a Arguição de 
Descumprimento de Preceito Fundamental 54, o aborto passou a ser permitido também seo feto for diagnosticado com anencefalia(BRASIL, 2018b). Nesses casos, a lei não deixa de considerar o aborto um crime, apenas não é passível de punição se realizado, exclusivamente, por um médico.

Apesar de proibido, a lei não inibe a prática do aborto. No Brasil, estima-se que uma a cada cinco mulheres de até quarenta anos já praticou aborto em algum momento de sua vida, sendo mais frequente entre aquelas com até 24 anos, moradoras de centros urbanos e com menor grau de escolarização. Estima-se que em 2015 aconteceram mais de 500 mil abortos, metade pela via medicamentosa (DINIZ et al., 2017). Tal situação representa a quinta maior causa de internações na rede pública de saúde e a terceira causa de morte materna (BRASIL, 2009). Ainda sobre as estatísticas, as que mais morrem são as jovens, de estratos sociais desfavorecidos, residentes em áreas periféricas das cidades. Em relação às diferenças de etnia e cor, registra-se que as mulheres negras apresentam um risco três vezes superior de morrer do que as brancas (MENEZES; AQUINO, 2009), evidenciando a gravidade da situação, pois indica o risco a que essas mulheres estão submetidas ao realizar o aborto inseguro.

Em 1994, a Conferência Internacional de População e Desenvolvimento (CIPD), realizada, no Cairo, considerou o aborto inseguro como grave problema de saúde pública. Em 1995, na Conferência Mundial sobre a Mulher, em Pequim, foi recomendado aos países que considerassem a revisão das leis que contivessem medidas punitivas contra as mulheres submetidas a abortamentos ilegais (FUSCO et al, 2008). Ainda no âmbito das agendas internacionais, sobre o tema, destaca-se o conjunto de Objetivos de Desenvolvimento Sustentável, a serem alcançados até ano de 2035. No objetivo 3 - saúde e bem-estar para todos, encontramos meta referente à redução da mortalidade materna (causada por condições relacionadas à gestação, parto e puerpério) não sendo aceitável mais que 70 mortes de mulheres para cada 100 mil nascidos vivos.No caso do aborto, uma importante causa de morte de gestantes, o desafio está em estabelecer políticas públicas de saúde que protejam 
as mulheres em cenários culturais e institucionais pouco permeáveis a aceitação da prática como um direito reprodutivo (OMS, 2014).

No Brasil, o tema ficou em evidência nos primeiros dias de agosto de 2018, tendo em vista que nos dias 3 e 6 desse mês, o Supremo Tribunal Federal promoveu audiência pública a respeito da descriminalização do aborto, desde que realizado até a décima segunda semana de gestação. A audiência foi convocada para a preparação do julgamento de Arguição de Descumprimento de Preceito Fundamental 442, que foi ajuizada pelo Partido Socialismo e Liberdade (PSol), em conjunto com a Anis - Instituto de Bioética, Direitos Humanos e Gênero ${ }^{8}$, que questiona os artigos 124 e 126 do Código Penal, nos quais o aborto é criminalizado $\mathrm{e}$ as mulheres que $\mathrm{o}$ praticam, voluntariamente, são penalizadas. O pedido é para que se exclua desses artigos a prática do aborto, tendo em vista que viola princípios fundamentais, como a dignidade da pessoa humana, a cidadania, a

\footnotetext{
8 Organização feminista, não-governamental e sem fins lucrativos, fundada em 1999, em Brasília. Maiores informações em:
}

inviolabilidade da vida, a liberdade, a igualdade, a proibição de tortura ou tratamento desumano e degradante, a saúde, o planejamento reprodutivo das mulheres, além dos direitos sexuais e reprodutivos (BRASIL, 2018c).

De acordo com o Supremo Tribunal Federal (BRASIL, 2018c), sessenta especialistas do Brasil e do exterior foram ouvidos nos dois dias de audiência. Dentre eles, pesquisadores de diversas áreas, profissionais da saúde, juristas, advogados, representantes de organizações da sociedade civil de defesa dos direitos humanos e de organizações religiosas. Neste âmbito, havia representantes do Ministério da Saúde, da Federação Brasileira das Associações de Ginecologia e Obstetrícia (FEBRASGO), da Academia Nacional de Medicina, da Fundação Oswaldo Cruz (FIOCRUZ), do Conselho Federal de Psicologia (CFP) e da Conferência Nacional dos Bispos do Brasil (CNBB).

$\mathrm{Na}$ Argentina, por sua vez, no dia 8 de agosto de 2018, foi realizada votação, na câmara de senadores do país,

http://www.bioetica.org.br/?siteAcao=BioeticaB $\underline{\text { rasilIntegra\&id }=26}$ 
do projeto de lei que regulamentaria o aborto desde que realizado até o décimo quarto mês de gestação, designado nos termos de Interrupção Voluntária da Gravidez. Após 17 horas de debate, a decisão foi pela rejeição do projeto, com 38 senadores manifestando voto contrário à legalização, 31 a favor e 02 abstenções (ARGENTINA, 2018).

A audiência pública realizada pelo STF e a votação da lei que descriminalizaria a prática do aborto no Senado argentino marcaram o período como um dos mais emblemáticos sobre esse tema na América Latina. A repercussão desses acontecimentos foi amplamente publicizada por diferentes meios de comunicação e redes sociais.

$$
\text { Considerando as reações }
$$
deflagradas na sociedade e o modo como a mídia vem abordando o tema, pretendemos, neste artigo, identificar e analisar as reportagens sobre o aborto em dois jornais de ampla circulação nacional - Folha de São Paulo e El País Brasil $^{9}$,em suas versões online, de 12 de julho a 13 de agosto de 2018.

\footnotetext{
${ }^{9}$ A partir de agora, usaremos a sigla FSP para nos referir à Folha de São Paulo e EP para nos referir ao El País.
}

\section{Procedimentos Metodológicos}

Trata-se de uma pesquisa documental, exploratória e descritiva, de abordagem mista (qualitativa e quantitativa). Os dados foram coletados na mídia, incluindo dois jornais de ampla circulação, a Folha de São Paulo (FSP) e o El País (EP).

O levantamento ocorreu entre 12 de julho e13 de agosto de 2018, considerando o período da realização das audiências públicas pelo STF, dia 3 e 6 de agosto e, também, a votação, realizada no Senado argentino no dia 8 de agosto, a respeito do aborto.Foram selecionados, classificados e analisados textos publicados nas versões online. Definimos um período de trinta dias para a coleta das reportagens, aproximadamente quinze dias antes e quinze dias depois dos eventos supracitados.

A palavra-chave utilizada para a pré-seleção das reportagens, realizada por meio dos mecanismos de busca dos próprios jornais citados, foi "aborto". Após a pré-seleção (132 reportagens na 
FSP e 13 no EP), foram lidas todas as matériase excluídas66 da FSP, pois se referiam somenteà palavra "aborto" no texto, mas não tratavam especificamente do tema. Todas as reportagens do EP foram incluídas nas análises. $\mathrm{O}$ levantamento das reportagens, durante a fase de pré-seleção, foi feito por uma das autoras. Na segunda fase, quatro autores realizaram a análise das reportagens selecionadas. Por fim, todos os autores foram mobilizados para que se estabelecesse o consenso sobre as temáticas em destaque, o que resultou na elaboração das categorias analíticas.

A FSP, como um dos jornais de maior tiragem no Brasil, foi escolhida em função de sua notoriedade $\mathrm{e}$ importância, dentre os jornais brasileiros, características que tendem a influenciar na construção de uma opinião pública acerca do que é noticiado. O EP, por sua vez, é um jornal diário, de grande circulação na Espanha e que tem uma edição específica voltada para o Brasil, veiculada em português. Ambos têm motores de busca por palavras-chave, o que facilitou a nossa estratégia de coleta e seleção das reportagens. Salientamos que o EP tem acesso totalmente gratuito a todas as suas páginas. A FSP, no entanto, permite o acesso irrestrito somente aos assinantes do jornal.

Foi estabelecido um roteiro para a coleta das informações nos textos selecionados, incluindo os seguintes itens: data da publicação; título; autoria; seção; abordagem temática principal; e, sujeitos das reportagens (quem fala sobre o tema).

Os dados coletados foram apresentados, a seguir, de forma descritiva, privilegiando-se a análise temática acerca das reportagens analisadas. A construção das categorias analíticas foi realizada com base em Minayo (2014): primeiro foi feita uma leitura flutuante do material para, depois, serem definidas as categorias analíticas e, por fim, realizada a análise do conteúdo.

\section{Resultados}

Foram publicadas, nos dois jornais pesquisados, 79 reportagens (66 da FSP e 13 do EP), durante o período definido. Destas, mais de $35 \%(n=29)$ referiam-se à votação do aborto na Argentina. 
Figura 1 - Reportagens publicadas na Folha de São Paulo e no El País sobre o aborto, entre12/07/2018 e 13/08/2018

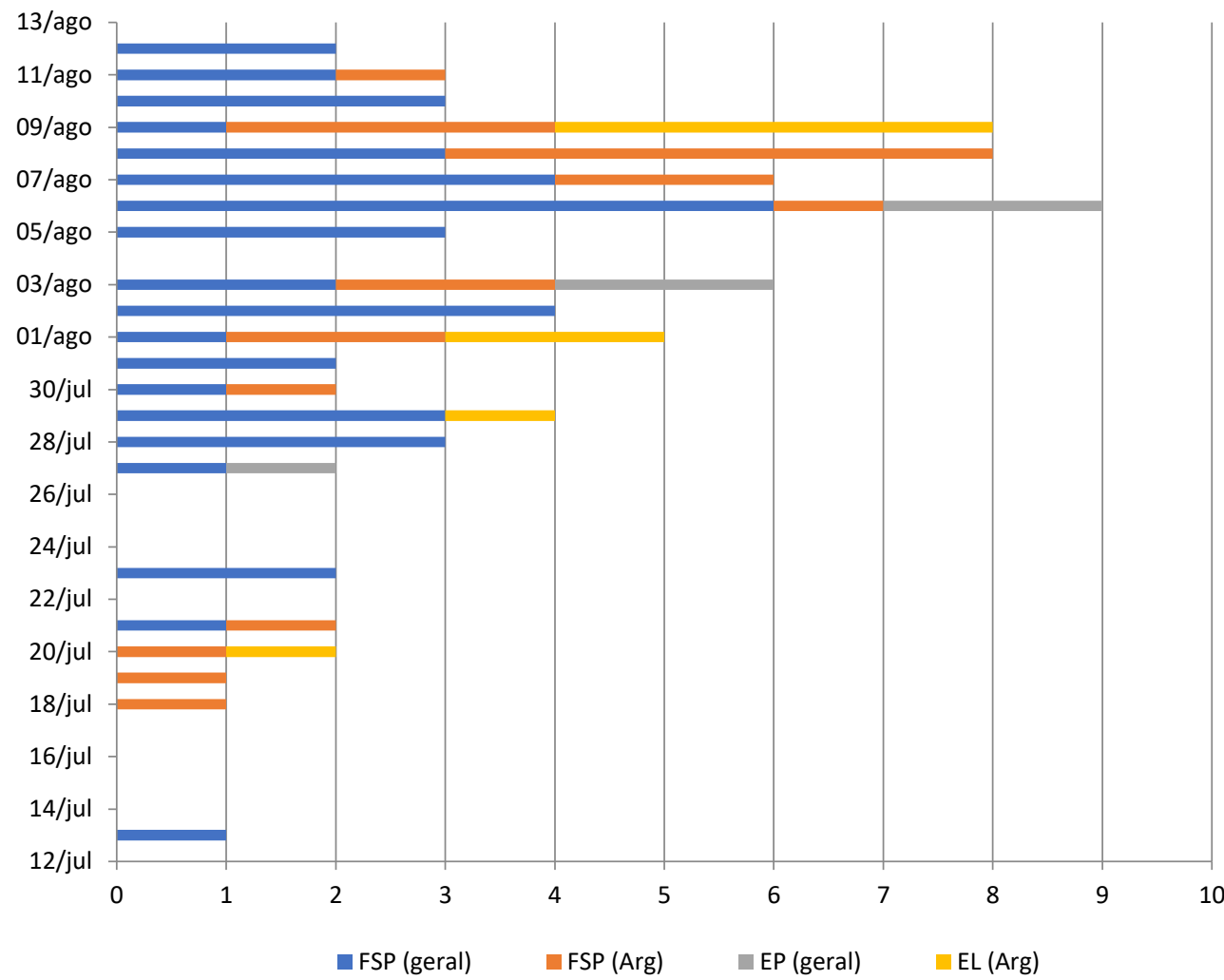

Fonte: Dados da pesquisa (2018)

O maior número de reportagens foi publicado no dia 6 de agosto, certamente, em virtude das audiências realizadas pelo STF e da votação a respeito do tema no Senado argentino. Verificamos que o período de maior concentração de publicações foi entre $1^{\circ}$ e 9 de agosto, representando a metade do total levantado.

As sessões em que as reportagens foram publicadas, na FSP, em sua maioria, foram Colunas, Blogs, Mundo e Cotidiano. Já no EP, foram Notícias e Internacional. Entre os sujeitos que se manifestaram nas reportagens (opiniões e entrevistas) estão representantes de governos, de movimentos sociais, de agências internacionais, além de religiosos, cientistas, ativistas dos Direitos Humanos,pesquisadores e escritores.

Com relação às abordagens temáticas, predominaram as seguintes: Legislação e regulamentação do aborto no Brasil; Legislação e regulamentação do aborto na Argentina; Legislação e regulamentação do aborto no Mundo; Transição de governo no Brasil e 
posicionamento de candidatos sobre o aborto; Iniquidades nas consequências da criminalização do aborto; e
Intolerância ao posicionamento pródescriminalização do aborto.

\section{Figura 2 - Temáticas das reportagens publicadas na Folha de São Paulo e no El País sobre o aborto, de 12/07/2018 a 13/08/2018}

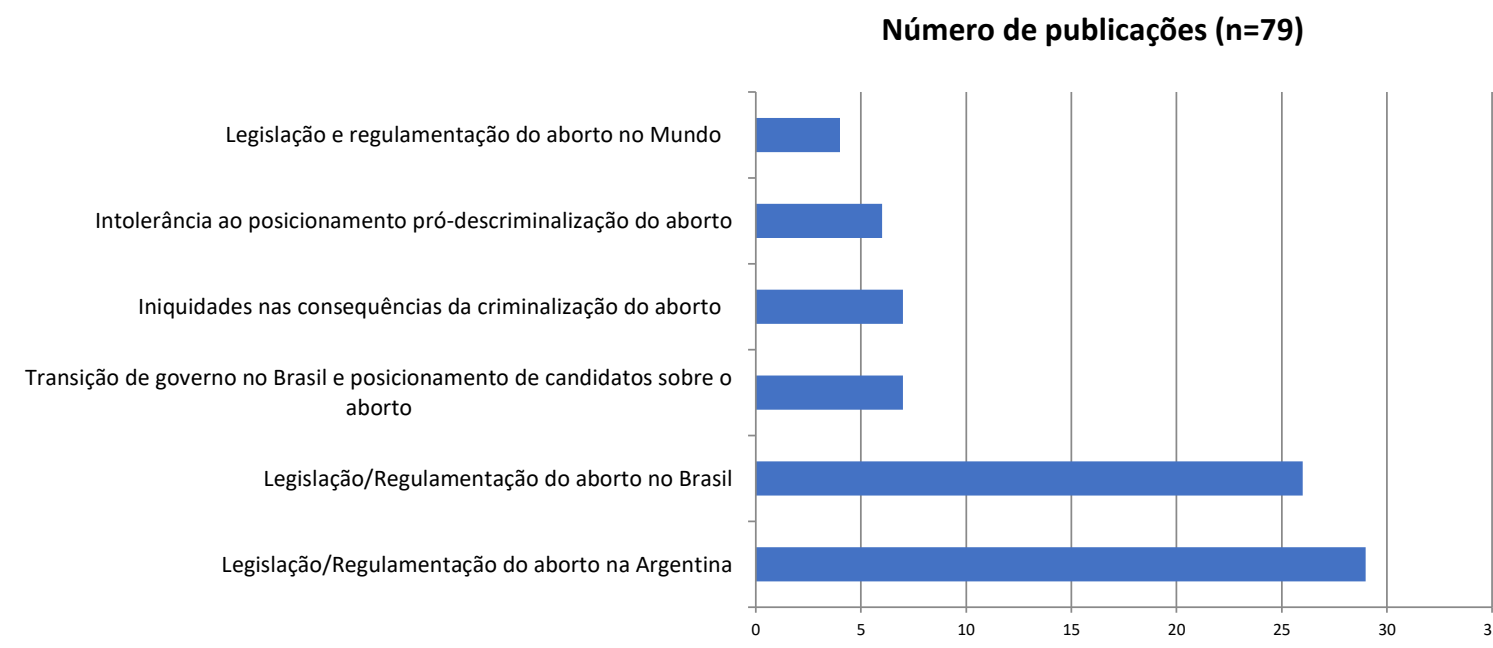

Fonte: Dados da pesquisa (2018)

Das temáticas arroladas acima, a que mais se destaca é a relativa à Legislação/Regulamentação do aborto na Argentina, que totalizou 29 reportagens $(36 \%)$, seguida da relativa ao mesmo tema no Brasil, com 26 reportagens $(33 \%)$.

De forma geral, as reportagens sobre 0 aborto na Argentina apresentaram o cenário envolvendo a votação da legalização do aborto até o décimo quarto mês de gestação, os grupos contrários à aprovação da lei (celestes) e a favor (verdes). Trouxeram a tensão envolvendo o governo, personalizado no presidente Macri, quem permitiu que a discussão sobre o aborto viesse à tona, e a Igreja, principalmente na pessoa do atual Papa Francisco, que é argentino. Além disso, algumas reportagens abordaram sobre o cenário que envolveu a possibilidade de se discutir essa lei, um país que enfrenta uma grave crise econômica e um presidente tentando aumentar a sua popularidade.

A análise das reportagens selecionadas nos permitiu elaborar quatro categorias que versam sobre:Guerra fria dos discursos, Aborto 
e o cabo de guerra entre Saúde Pública e Segurança Pública, Aborto nas pautas de candidatos(as) à Presidência do Brasil e Feminismos e aborto, discutidas a seguir.

\section{Guerra fria dos discursos}

Dentre as notícias veiculadas, a polarização dos discursos foi marcada pela contraposição entre agentes conservadores, atravessados fortemente pela ordem do discurso religioso e, progressistas, baseados em evidências científicas acerca do aborto.

Assim como na Guerra Fria da segunda metade do Século XX, os dois lados não se enfrentam diretamente, mas buscam angariar mais adeptos para o seu lado, em diferentes esferas de disputa, como a própria audiência pública do STF. De um lado, representantes de organizações religiosas que lançam mão de estratégias imagéticas para "tocar corações": fetos de borracha e fotos de crianças recém-nascidas são alguns exemplos. A vida do feto emerge como um argumento primordial no convencimento, pois deve ser preservada e garantida.

Por outro lado, estão cientistas e instituições que demonstram, estatisticamente e pela experiência de outros países, as vantagens de retirar a prática do aborto do rol de crimes puníveis com prisão. Débora Diniz, professora da Universidade de Brasília, é citada diversas vezes nas reportagens selecionadas, seja falando em primeira pessoa, ou como a terceira pessoa - de quem se fala. Em uma entrevista no EP, ela busca redirecionar tal guerra fria, apontando para outros significados possíveis do aborto:

Reconhecer que o aborto é um fato da vida reprodutiva das mulheres não significa ser contra ou a favor do aborto, ou contra ou a favor das religiões. (EP, Opinião, 6 Ago. 2018)

Interessante notar que, diferente de outros temas que foram analisados por caminhos metodológicos semelhantes (FARIA et al., 2018; TEO, 2010, NOTO et al., 2003), nesta pesquisa identificamos a preponderância do gênero "Coluna" na comunicação midiática sobre aborto, tanto no EP quanto na FSP. Tal fato indica que a guerra fria discursiva foi, majoritariamente, disputada por meio de opinião de especialistas em saúde reprodutiva, de jornalistas e de ativistas.

A coluna "Análise" da FSP intitulou alguns textos com a frase 
"Questões de ordem", a qual narra essa polarização dos debates durante a audiência pública no STF e, principalmente, a diversidade dentro da polarização. As discussões vão além do contra e a favor - há um contínuo de sujeitos e discursos entre tais extremos.De qualquer forma, é preciso atentar para o fato de que a metáfora da guerra fria discursiva também precisa ser relativizada, pois não são duas partes bem definidas que, de seus extremos, disputam o "centrão". De fato, são uma multiplicidade de práticas discursivas de diferentes origens que se materializam nas reportagens publicadas.

Por fim, a polarização dos posicionamentos sobre o tema nos levou a resgatar uma disputa discursiva que atravessa os tempos. Trata-se da narrativa religiosa sobre a natureza humana e os novos códigos de sociabilidade inaugurados na modernidade com o advento do conhecimento científico. O debate em torno do aborto talvez seja, atualmente, um dos que mais suscita a tensão entre essas duas narrativas e suas ambições: de um lado técnicos e cientistas se apoiam nas evidências para reduzir mortalidade materna e diminuir o estigma das
94 mulheres; de outro, entre os representantes de diversas religiões, prevalece o discurso da gestação como o sagrado, a célula como vida (feto em desenvolvimento) e a mulher como pecadora e merecedora de punição quando infringe as leis divinas. $\mathrm{O}$ fato é que esse conflito de ideias, ora acirrado, ora velado através da história, não está produzindo o avanço ético necessário à questão do aborto. Certamente, a ausência de consenso tem alimentado uma das principais distorções em relação ao aborto que é a de priorizar adiscussão sobre o crime cometido e não sobre a prevenção de agravos às mulheres que realizam o procedimento em condições inseguras.

\section{Aborto e o cabo de guerra entre Saúde Pública e Segurança Pública}

O aborto, tanto no Brasil quanto na Argentina, é primordialmente tratado como um tema de Segurança Pública, em função dele ser criminalizado nos dois países. Em ambos, há legislação específica no Código Penal que proíbe a prática. Notícias do período pesquisado evidenciaram que é preocupante a mortalidade materna relacionada ao aborto inseguro e classificaram tal 
situação como um problema de saúde pública, devido ao impacto nos indicadores de saúde:

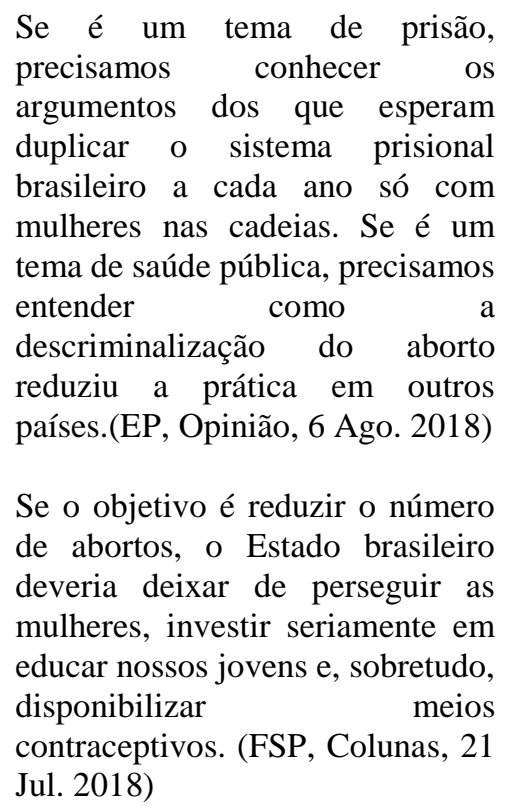

Aparentemente, não há mulheres presas no Brasil por aborto. A pena não é alta (detenção de um a três anos) para os padrões atuais de encarceramento. Não é o que move a reforma. Porém, a submissão a interrogatórios e a procedimentos periciais deixa marcas inaceitáveis na mulher. O problema é de saúde pública. (FSP, Colunas, 11 Ago. 2018)

Os óbitos maternos decorrentes de aborto inseguro são difíceis de mensurar, pois a prática é ilegal, (RESENDE et al., 2016).Segundo dados do Ministério da Saúde, o abortamento representa uma das principais causas de mortalidade materna no Brasil, em torno de $12,5 \%$ do total desses óbitos. Apesar destas estimativas, não se sabe, exatamente, quantas mulheres vivenciam o aborto ou quantas morrem anualmente por causas relacionadas às suas complicações, pois, ocorre predominantemente na clandestinidade (DOMINGOS, 2010; DINIZ et al., 2017).

O aborto é considerado um evento comum na vida das mulheres (DINIZ; MEDEIROS, 2010) e, devido à sua complexidade, a discussão acerca do tema envolve aspectos legais, morais, religiosos, sociais e culturais (BRASIL, 2011; BRASIL, 2009).

Ainda que o abortamento seja considerado um grave problema de saúde pública, sobretudo nos países onde é criminalizado, com a ascensão do movimento feminista, a partir das décadas de 1960 e 1970, e, graças a isso, com a vigente posição da mulher na sociedade, o tema aborto passou a ser mais recorrente.

No Brasil, o feminismo recebeu influências do feminismo internacional, buscando maior interlocução entre direitos individuais e direitos sociais, de modo a diminuir as desigualdades sociais. Assim, a luta pela descriminalização do aborto tornou-se uma marca do movimento feminista no Brasil ao considerar o aborto como um 
direito individual - "nosso corpo nos pertence", dizem as mulheres do movimento - e direito social, o qual questiona as condições precárias em que ele é realizado no país, arriscando a saúde e a vida das mulheres (REBOUÇAS, 2011).

Cabe aqui ressaltar uma última questão relacionada à captura do tema do aborto pelos discursos e práticas de segurança pública. $\mathrm{O}$ fato de focar $\mathrm{o}$ debate na criminalização e não na assistência em saúde a mulheres que desejam ou realizam a prática tem diminuído as possibilidades, até mesmo, de informar as mulheres e os profissionais sobre as situações em que o aborto pode ser feito dentro da lei. Chama a atenção particularmente a falta de informação sobre a rede de assistência disponível e sobre como proceder em casos de violência sexual que resulta em gravidez. Há protocolos que orientam sobre o tempo hábil para o uso de contracepção de emergência e, no caso de uma gestação confirmada, para a realização de procedimento que a interrompe. Há também profissionais que insistem que a vítima apresente

10 São eles: Ciro Gomes (PDT), Guilherme Boulos (PSOL), Vera Lúcia (PSTU) e João boletim de ocorrência e laudo do exame de corpo de delito para comprovar a violência sofrida. Muitas vezes, essas barreiras ampliam o tempo de espera para a realização do procedimento agravando a situação da mulher, pois com o avançar da idade gestacional, o procedimento passa a não ser mais permitido.

\section{Aborto nas pautas de candidatos(as) à Presidência do Brasil}

No ano de 2018, tivemos eleições gerais no Brasil (Presidente da República, Governadores dos Estados, Senado e Câmaras Federal e Estaduais). Concorrendo a Presidente, tivemos um total de treze candidatos. Desses, apenas cinco citavam a prática do aborto em seus planos de governo, sendo que quatro deles se referiam à importância de se garantir condições legais e de recursos para a interrupção da gravidez, combatendo a criminalização das mulheres ${ }^{10}$.

No entanto, um deles - Cabo Daciolo (Patriota) - diz em seu programa que “(...) não é possível conceber que a família em seus moldes naturais seja

Goulart Filho (PPL), de acordo com seus planos de governo (RONCOLATO, 2018). 
destruída, que a ideologia de gênero e a tese de legalização do aborto sejam disseminadas em nossa sociedade como algo normal (...). Isso não é laicidade. É a desmoralização da Pátria” (RONCOLATO, 2018, p.9).

Nas reportagens selecionadas, alguns candidatos (e suas posições a respeito) são mencionados, ainda que tal tema não esteja presente em seus planos de governo:

Meirelles foi evasivo ao ser questionado sobre sua opinião pessoal acerca do tema, mas reconheceu ser um problema de saúde pública. Por um lado, disse ser a favor do direito à vida, mas ponderou que defende também os direitos individuais. (FSP, Eleições 2018, 6 Ago. 2018)

O candidato [Jair Bolsonaro] afirmou à Folha (...) que "não compete ao outro lado", o do homem, dizer se a mulher deve ou não interromper a gravidez. (...) se eleito chefe do Executivo, exerceria seu poder presidencial e vetaria uma lei pró-aborto eventualmente aprovada pelo Congresso. (FSP, Eleições 2018, 7 Ago. 2018, grifos no original)

E mesmo para aqueles candidatos que já se posicionaram a favor em seus planos de governo, como é o caso do Ciro Gomes, parece haver contradições:

O rascunho do programa não menciona a palavra "aborto" e apenas diz que Ciro terá como meta a "garantia de condições legais e de recursos para a interrupção da gravidez quando ocorrer de forma legal, combatendo a criminalização das mulheres atendidas nos pontos de atendimento na saúde". (FSP, Eleições 2018, 11 Ago. 2018, grifos no original)

A vice na chapa de Ciro disse ainda que "todas as mulheres e homens do Brasil são contra o aborto" e fez questão de ressaltar ter votado contra a descriminalização do aborto em caso de anencefalia (...). (FSP, Eleições 2018, 8 Ago. 2018 atualizado em 9 Ago. 2018, grifos no original)

A recorrência deste e de outros temas se apresenta como questionamentos às pessoas que almejam o cargo de chefia do Executivo nacional, pois reflete não apenas a escolha entre duas respostas - sim ou não - mas exprime quais práticas discursivas estão atravessadas nessa candidatura. Isso pode levar a suposições de como será seu governo.

Por isso, queremos saber como cada candidato entende a questão do aborto - se como questão de saúde pública, de direitos fundamentais ou de política criminal. (EP, Opinião, 6 Ago. 2018)

Não é de agora que o tema do aborto aparece a cena política brasileira: nos anos 1990 houve tentativa de avanços no que tange aos direitos das mulheres, época, portanto, muito 
propicia para esse debate devido à recente redemocratização.

Já nos anos 2000 houve numerosas reações conservadoras, sustentadas por representantes das Igrejas Católica e Protestante, no sentido de recuar o que chamavam de atentados à moral (MIGUEL et al., 2017). A atual década está marcada pelo desvelamento das contradições, em que candidatos/as, pretensamente uníssonos/as, discordam em pontos de suas campanhas, defendendo a vida de uns/umas (no caso, do feto), em detrimento de outras vidas (AVERBUCK, 2018), conforme também apontado a seguir:

Mas não esqueçamos: o
reducionismo dos grupos pró-vida
que chamam as feministas de
assassinas é, em si, mais agressivo
que o exercício de escolha. É um
discurso de ódio. É o oposto de
tudo o que dizem defender. (FSP,
Coluna Antonia Pellegrino e
Manoela Miklos, 6 Ago. 2018)

Sendo assim, as candidaturas posicionam-se diferentemente em relação ao aborto, tanto quanto mais ou menos favoráveis forem seus nichos eleitorais, uma vez que grupos religiosos, científicos, empresariais, entre outros setores sociais, compartilham preferências e podem influenciar fortemente $\mathrm{o}$ desfecho eleitoral.

\section{Feminismos e aborto}

Outra categoria que emergiu do corpus analítico foi a ligação entre os feminismos e o aborto. A pluralização desses feminismos é devida por haver, sob esse guarda-chuva, várias práticas e teorias que refletem, cada uma, suas demandas espaço-temporais (COSTA, 2004).

É atribuída ao feminismo a luta pelo direito à integridade corporal, à igualdade, à individualidade e à diversidade (PIMENTEL; VILLELA, 2012), materializados no fenômeno aborto:

(...) o debate vem se acirrando no Brasil, empurrado por um emergente movimento feminista no país e no mundo e pelas inúmeras manifestações, nas ruas e nos espaços de discussão, favoráveis à interrupção da gravidez. (EP, Brasil, 3 Ago. 2018)

A Campanha pelo Direito ao Aborto é uma articulação nacional que sai dos encontros nacionais de mulheres e que têm 13 anos de desenvolvimento. (...) tem que (...) foi a transformação dessas mobilizações em paralisações de mulheres, que foram tomadas como uma ferramenta que interpelou setores que antes não se consideravam feministas, como as sindicalistas, outros movimentos 
sociais. (EP, Feminismo, 1 Ago. 2018)

A autora do último excerto é Marta Dilon, nomeada como criadora do Movimento Ni Una Menos que busca modificar o atual cenário feminicida na Argentina e que alcançou outros países como Brasil e Uruguai.

Percebe-se que o aborto, e juntamente com ele certas práticas reivindicadas pelas feministas, partem das mulheres em assembleia e atravessa espaços de lutas em outros âmbitos como a luta de classe ou por direitos sociais, tornando o tema mais amplo. Isso provoca respostas mais agressivas, com vistas a impedir a "onda verde", conforme o trecho a seguir relata:

$\mathrm{Na}$ marcha [feminista] houve contra-manifestações, algumas organizadas pelo Movimento Social Patriótico, um grupo autodefinido como "nacionalista, independente e antiditadura gay" (...). Através das redes sociais, as mulheres mostraram a fotografia de um cartaz que propunha a "esterilização gratuita para as feministas". (EP, Internacional, 27 jul. 2018, grifos no original)

Estão presentes no excerto algumas estratégias hegemônicas como lemas moralizantes e violentos, pois associam ontologias com regimes de exceção - o que aliás é o que o Movimento Social Patriótico justamente almeja e propõe que as ideias que ameaçam sua estabilidade permaneçam na arena discursiva e, para isso, defendem que aqueles que enunciam tais discursos não se reproduzam.

Outra via de deslegitimação dos feminismos é a apropriação de suas conquistas por oportunismos políticos, como apontado a seguir:

Temos muito claro que se conseguirmos a lei do aborto, não foi o macrismo ou qualquer outro Governo que conseguiu, mas os movimentos de mulheres. (EP, Cultura, 29 Jul. 2018)

Essa entrevista aconteceu antes da decisão do Senado argentino em manter a criminalização do aborto. Nela, Marta Dilon explicita sua preocupação de que seja atribuído a outros sujeitos que não às mulheres - a possível vitória. Esses outros sujeitos são representados, metonimicamente, pelo macrismo, programa político argentino, liderado por Maurício Macri, ex-prefeito de Buenos Aires e atualmente presidente do país. O macrismo é caracterizado como populismo de direita, de vertente neoliberal, que busca abrir amplamente os negócios com outros países e acabar com a pobreza (CALDERÓN, 2017; STOPANI et al., 2017). 
Enquanto isso, na arena discursiva brasileira, o relato de como geralmente acontece o debate em torno do aborto reafirma certas posições a que o feminismo e, consequentemente, as mulheres são imputadas:

As razões contra a legalização não eram apenas superficiais, mas egoístas. É só se prevenir. Feto é vida. Aborto é assassinato. Quem mandou abrir as pernas? É só dar pra adoção. Não quero ter filho, não transe. É esse o nível do "diálogo". A culpa é sempre da mulher. (FSP, Colunas, 2 Ago. 2018, grifo no original)

A citação acima é apenas um exemplo de uma prática social baseada no patriarcado, sistema social androcêntrico, que concede ao homem o direito de determinar a vida de mulheres de forma abjeta e qualquer discurso que permita o enfraquecimento deste poder é diminuído, invisibilizado ou tratado de forma a tornar-se impassível de crédito (BARRETO, 2004; BUTLER, 2015).

No caso do aborto, a maioria dos argumentos trazidos nas reportagens julga como culpada a mulher que não deseja estar grávida naquele momento, levando a crer que todos os atos que levam a uma gravidez são de responsabilidade única da mulher - mais uma vez - e seu suposto papel reprodutor é evidenciado em detrimento da gama de
100

direitos que cercam este corpo. A mídia contribui bastante nesse sentido, pois, ao reforçar certas práticas discursivas, reproduz e expande sua opinião sobre quem precisa, ou melhor, merece proteção.

A criminalização do aborto leva as mulheres a uma divisão classista, pois a existência da previsão de prisão para quem o pratica de modo algum irá impedir o fenômeno. Dessa maneira, será a capacidade financeira que irá definir a prática do aborto: se clandestino e de alto risco no país de origem ou, em outro país, legal, seguro e economicamente viável para poucas. Isso leva ao argumento do excerto a seguir:

(...) não há Ni Una Menos se há aborto clandestino porque enquanto morrem mulheres por causas totalmente evitáveis como o acesso ao aborto, considero que são feminicídios de Estado. (EP, Feminismo, 1 Ago. 2018)

Falar de aborto é, segundo o corpus analisado, falar de feminismos, já que as lutas desses movimentos, apesar de múltiplas em diversas esferas, se baseiam na autoafirmação da mulher perante a sociedade e perante si mesma.

A gravidez, materializada no corpo feminino, é um fenômeno atravessado por ideologias que buscam 
conformá-lo em certos limites, sempre a serviço de algo. $\mathrm{O}$ aborto pode ser entendido, nesse contexto, como uma negativa da conformação patriarcal. E nesses termos, avançar no debate sobre esse tema, exige, igualmente, avançar em mudanças culturais que repercutam no alcance da igualdade entre mulheres e homens, respeitados em suas diversidades étnicas, raciais, sexuais, religiosas e em suas lutas por uma vida digna em contextos de fragilidade social e econômica.

\section{Considerações finais}

O tema central da análise aqui proposta - o aborto - ganhou notoriedade nas páginas dos jornais analisados durante as duas primeiras semanas do mês de agosto de 2018, decorrente da realização das audiências públicas realizadas pelo STF, no Brasil, e da votação pela sua descriminalização no Senado argentino.

Embora a mídia tenha oportunizado a manifestação de diferentes grupos, a favor e contra, à prática da interrupção voluntária da gravidez, os discursos dos grupos favoráveis são apresentados, tal como em pesquisa anterior realizada sobre o tema (SOUZA e BRANDÃO, 2012), de forma pouco veemente.

$\mathrm{Na}$ maior parte das vezes, são reproduzidos argumentos pouco fundamentados ou esclarecedores e, quando são apresentados argumentos favoráveis à prática, trata-se de “opiniões", publicadas em colunas pessoais, de especialistas, jornalistas ou ativistas.

A presença tímida do tema nos planos de governo à Presidência da República pode guardar relação com o período pré-eleitoral, sem a definição de candidaturas homologadas pelo Tribunal Superior Eleitoral (TSE), o que só veio a ocorrer em 15 de agosto de 2018 (BRASIL, 2018b). Ainda assim, mesmo para os candidatos que apresentaram em seus planos de governo uma posição objetiva a respeito da descriminalização, as reportagens não argumentaram positivamente a respeito.

Em relação ao feminismo, diferentemente do encontrado em pesquisa semelhante (SOUZA e BRANDÃO, 2012), os textos das reportagens aqui analisados parecem contribuir para a promoção da saúde sexual e reprodutiva, em uma perspectiva da autonomia feminina. Ao 
evidenciar a existência de grupos, ainda que minoritários, na defesa dos direitos sexuais e reprodutivos, dá "voz" ou amplia a possibilidade de que leitores e leitoras conheçam e saibam sobre. Mesmo que, por outro lado, a reação contrária a estes grupos (e seus argumentos a favor da penalização das mulheres e da continuidade da criminalização dessa prática) ainda ocupem muitas páginas de jornais.

\section{Referências}

ANIS, Instituto de Bioética, Direitos Humanos e Gênero [organizador] Aspectos éticos do atendimento ao aborto legal: perguntas e respostas. Brasília: Letras Livres, 2012.

ARGENTINA. Senado. Noticias. Se rechazó el proyecto de interrupción voluntaria del embarazo. Disponível em: $<$ http://www.senado.gov.ar/prensa/1663 1/noticias>. Acesso em: 15 oct. 2018.
AVERBUCK, Clara. Pró-vida de quem?

Disponível

em: <https://www.cartacapital.com.br/blogs/ feminismo-pra-que/pro-vida-de-quem3001.html>. Acesso em 29 set. 2018.

BARRETO, Maria do Perpétuo Socorro Leite. Patriarcalismo e o Feminismo: uma retrospectiva histórica, Revista Ártemis, João Pessoa, v.1, p. 64-73, Dz. 2004.

BRASIL. Código Penal. Decreto-Lei ${ }^{\circ}$ 2.848, de 7 de dezembro de 1940 . Disponível em:<http://www.planalto.gov.br/ccivil_ 03/decreto-lei/del2848.htm>. Acesso em: 20 jul. 2018.

BRASIL. Ministério da Saúde Secretaria de Ciência, Tecnologia e Insumos Estratégicos. Departamento de Ciência e Tecnologia. Aborto e saúde pública no Brasil: 20 anos. Brasília: Ministério da Saúde, 2009.

BRASIL. Ministério da Saúde. Atenção humanizada ao abortamento: norma técnica. 2. ed. Brasília: Ministério da Saúde, 2011. 
BRASIL. Tribunal Superior Eleitoral. Tudo o que você precisa saber sobre registro de candidatura. Disponível em: <http://www.tse.jus.br/imprensa/noticia s-tse/2018/Janeiro/resolucao-defineregras-para-escolha-e-registro-decandidatos-nas-eleicoes-de-2018>. Acesso em: 25 ago. 2018a.

BRASIL. Superior Tribunal Federal. Arguição de Descumprimento de Preceito Fundamental 54 Distrito Federal. Voto do Ministro Relator Marco Aurélio. 12abr. 2012.

Disponível

em: <redir.stf.jus.br/paginadorpub/paginado r.jsp?docTP=TP\&docID=3707334>.

Acesso em: 29set. 2018b.

BRASIL. Supremo Tribunal Federal. STF realiza audiência pública sobre descriminalização do aborto nos dias $3 e$ 6 de agosto. Disponível em: $<$ http://www.stf.jus.br/portal/cms/verNo ticiaDetalhe. asp idConteudo $=385093>$. Acesso em: 13 ago. 2018c.

BUTLER, Judith. Relatar a si mesmo. Crítica da violência ética. Belo Horizonte: Autêntica, 2015.
CALDERÓN, Emilse Eliana. Perfil interno da Política de Defesa Macrista e seu impacto em termos de inserção internacional: mais continuidades que mudanças. Austral: Revista Brasileira de Estratégia e Relações Internacionais, Porto Alegre, v.6, n.12, p.254-268, Jul./Dez. 2017.

COSTA, Suely Gomes. Movimentos feministas, feminismos. Estudos Feministas, Florianópolis, v. 12(N.E.), p. 23-36, set./dez. 2004.

DINIZ, Debora; MEDEIROS, Marcelo. Aborto no Brasil: uma pesquisa domiciliar com técnica de urna.Ciênc. Saúde Coletiva,Rio de Janeiro,v.15,supl. 1,p. 959-966,Jun.2010.

DINIZ, Debora; MEDEIROS, Marcelo; MADEIRO, Alberto. Pesquisa Nacional de Aborto 2016. Ciênc. Saúde Coletiva, Rio de Janeiro,v. 22, n. 2, p. 653660,fev.2017.

DOMINGOS, Selisvane Ribeiro da Fonseca; MERIGHI, Miriam Aparecida Barbosa. O aborto como causa de mortalidade materna: um pensar para o cuidado de enfermagem.Esc. Anna Nery, 
Rio de Janeiro, v.14, n. 1, p. 177-181, mar. 2010.

FARIA, Mateus Aparecido; ROCHA, Cristianne Maria Famer, BRITES, Liara Saldanha;MACHADO, Angela Maria Grando; SANTOS, Claiton Agnaldo Ribeiro; CECHINEL, Neuza de Freitas Raupp; MATIVI,Rossana dos Santos Rocha. Programa Mais Médicos e sua repercussão na mídia: o que informar e para quem?Revista Eletrônica de Comunicação, Informação e Inovação em Saúde, [S.1.], v. 12, n. 1, p.14-25, mar. 2018.

FUSCO, Carmen L. B.; ANDREONI, Solange; SILVA, Rebeca de Souza e. Epidemiologia do aborto inseguro em uma população em situação de pobreza Favela Inajar de Souza, São Paulo. Rev. bras. epidemiol.,São Paulo,v.11, n. 1, p. 78-88,mar.2008.

GANATRA et al. Global, regional, and subregional classification of abortions by safety, 2010-14: estimates from a Bayesian hierarchical model. Lancet, v. 390, p. 2372-81, 2018.
MENEZES, Greice; AQUINO, Estela

M. L. Pesquisa sobre o aborto no Brasil: avanços e desafios para o campo da saúde coletiva. Cadernos de Saúde Pública, Rio de Janeiro, v. 25, suppl 2. p. S193-S204, 2009.

MINAYO Maria Cecília de Souza. $O$ desafio do conhecimento: pesquisa qualitativa em saúde. São Paulo: Hucitec, 2014.

MONTEIRO Mario Francisco Giani, ADESSE Leila. Estimativas de aborto induzido no Brasil e Grandes Regiões (1992-2005). Anais do $15^{\circ}$ Encontro Nacional de Estudos Populacionais (ABEP), Caxambu, 2006.

MIGUEL, Luis Felipe; BIROLI, Flávia; MARIANO, Rayani. O direito ao aborto no debate legislativo brasileiro: a ofensiva conservadora na Câmara dos Deputados. Opin. Publica, Campinas, v. 23, n. 1, p. 230-260, Abr. 2017.

NOTO, Ana Regina et al. Drogas e saúde na imprensa brasileira: uma análise de artigos publicados em jornais $\mathrm{e}$ revistas.Cad. Saúde Pública, Rio de Janeiro, v. 19, n. 1, p. 69-79, fev. 2003. 
ORGANIZAÇÃO MUNDIAL DA SAÚDE (OMS). Abortamento seguro: Orientação técnica e de políticas para sistemas de saúde. 2ed. OMS: Genebra, 2013.

ORGANIZACIÓN MUNDIAL DE LA SALUD (OMS). Respeto de los derechos humanos al proporcionar información y servicios de anticoncepción: orientaciones y recomendaciones. OMS: Ginebra, 2014.

PIMENTEL, Silvia; VILLELA, Wilza. Um pouco da história da luta feminista pela descriminalização do aborto no Brasil. Cienc. Cult., São Paulo,v. 64,n. 2,p. 20-21, Jun. 2012.

REBOUÇAS, Melina Séfora Souza; DUTRA, Elza Maria do Socorro. Não nascer: algumas reflexões fenomenológico-existenciais sobre a história do aborto. Psicol. estud.,Maringá,v. 16,n. 3,p. 419-428, set. 2011.

RESENDE, Lilian Valim; RODRIGUES, Roberto Nascimento; FONSECA, Maria do Carmo. Morte materna por aborto. In: Anais do VII Congreso de laAsociaciónLatinoAmericana de Población e XX Encontro Nacional de Estudos Populacionais, Foz do Igauçu, 2016.

RONCOLATO, Murilo. Como os candidatos tratam da saúde nos planos de governo. Nexo, 28 ago. 2018. Disponível em:

$<$ https://www.nexojornal.com.br/expres so/2018/08/28/Como-os-candidatostratam-da-sa\%C3\%BAde-nos-planosde-governo>. Acesso em: 10 set. 2018.

SOUZA, R.A.; BRANDÃO, E.R. À sombra do aborto: o debate social sobre a anticoncepção de emergência na mídia impressa brasileira (2005-2009). Interface - Comunic., Saude, Educ., v.16, n.40, p.161-75, jan./mar. 2012.

STOPPAMI, Natalia; BAICHMAN, Alan; SANTOS, Jorge Alejandro. Política educativa y neoliberalismo: el rol del Estado, la lógica mercantil y la construcción de subjetividades durante el macrismo en la Argentina. Revista Pedagógica, Chapecó, v. 19, n. 42, p. 833, set./dez 2017. 
TEO, Carla Rosane Paz Arruda.

Discursos e a construção do senso comum sobre alimentação a partir de uma revista feminina.Saude soc., São Paulo, v. 19,n. 2,p. 333-346, Jun. 2010.

\section{Acervos digitais pesquisados}

EL PAÍS (EP). Disponível em: <https://brasil.elpais.com/>. Vários acessos de 12 jul. a 13 ago. 2018.

FOLHA DE SÃO PAULO (FSP).

Disponível

em:

$<$ https://www.folha.uol.com.br/>.

Vários acessos de 12 jul. a 13 ago. 2018. 